\title{
Arachnid types in the Zoological Museum of the Moscow State University. IV. Aranei 3 (Arachnida)
}

\section{Типы паукообразных в Зоологическом музее MГУ. IV. Aranei 3 (Arachnida)}

\author{
Kirill G. Mikhailov \\ К.Г. Михайлов
} Zoological Museum MGU, Bolshaya Nikitskaya Str. 2, Moscow 125009 Russia. E-mail: mikhailov2000@gmail.com
Зоологический музей МГУ, ул. Большая Никитская, 2, Москва 125009 Россия.

KEY WORDS: arachnids, Araneae, spiders, museum collections, types, holotypes, paratypes, syntypes, lectotype.

КЛЮЧЕВЫЕ СЛОВА: паукообразные, Araneae, пауки, музейные коллекции, типы, голотипы, паратипы, синтипы, лектотип.

ABSTRACT: A catalogue of 37 holotypes, 331 paratypes, 7 syntypes, one lectotype and 10 paralectotypes belonging to 50 spider species in nine families (Agelenidae, Atypidae, Cybaeidae, Gnaphosidae, Linyphiidae, Lycosidae, Nesticidae, Salticidae, Sparassidae) from the collection of the Zoological Museum of the Moscow State University is provided. Other depositories housing the remaining types of the listed species are given as well.

How to cite this article: Mikhailov K.G. 2019. Arachnid types in the Zoological Museum of the Moscow State University. IV. Aranei 3 (Arachnida) // Arthropoda Selecta. Vol.28. No.1. P.169-178. doi: 10.15298/arthsel. 28.1.16

РЕЗЮМЕ: Представлен список 37 голотипов, 331 паратипов, 7 синтипов, один лектотип и 10 паралектотипов, относящихся к 50 видам пауков (Aranei). Они принадлежат к девяти семействам (Agelenidae, Atypidae, Cybaeidae, Gnaphosidae, Linyphiidae, Lycosidae, Nesticidae, Salticidae, Sparassidae) и хранятся в Зоологическом музее МГУ. Также перечислены другие хранилища, в которых размещены другие типы указанных видов.

\section{Introduction}

This paper is the fourth in the series cataloging the arachnid types deposited in the Zoological Museum of the Moscow State University, continuing with the spider type collection, the largest one in the Museum. As indicated earlier [Mikhailov, Ivanov, 2018], Museum's invertebrate type collections include holo-, para- and syntypes of over 3,000 species, of which some 1,000 species belong to Aranei. The Museum's arachnid collection was founded in the 1860 s and currently con- tains more than 200,000 specimens, exclusive of Acari [Mikhailov, 2016a].

Traditionally, at least since the 1930s, the following handwritten documentation has been accepted in the Museum: (1) departmental register, (2) numerous inventory books on diverse invertebrate groups, and (3) type index cards (see Mikhailov [2018a] for further details). Unfortunately, only a small part of this documentation has been digitized to date (see Mikhailov [2016b] for further details). For spiders, index Ta is used in the inventory books of the Zoological Museum of the Moscow State University.

Altogether, the types of 50 species representing nine families (Agelenidae, Atypidae, Cybaeidae, Gnaphosidae, Linyphiidae, Lycosidae, Nesticidae, Salticidae, Sparassidae) are listed below, including 37 holotypes, 331 paratypes, 7 syntypes, 1 lectotype and 10 paralectotypes; 172 accession numbers have been allocated. The Museum card index of the spider type collection is arranged alphabetically, by genus name as originally described: Asthenargus Simon et Fage, 1922, Berlandina Dalmas, 1922, Bianor Peckham et Peckham, 1885, Bolyphantes C.L. Koch, 1837, Cedicus Simon, 1875, etc. The following list of types presents only species belonging to the genera whose names start from 'As' to ' $\mathrm{Ce}$ ' (the genera starting from $\mathrm{Ab}-\mathrm{Ak}$ are covered by Mikhailov [2018a] and Al-As by Mikhailov [2018b]).

\section{Methods}

The following sequence of data is accepted in the type catalogue: species name in the original description; a reference to the first description; transcription of data labels; list of other collections where the remaining types of the respective species are kept; remarks; current taxonomic status of the species. 
When necessary, label abbreviations are put in angled brackets, $<>$. Author's comments to the labels are given in square brackets, []. An English translation of the original Russian labels is provided in figure brackets, \{\} .

Museums or personal collections are abbreviated as follows: AP - personal collection of Alexander V. Ponomarev (Razdorskaya, Ust'-Donetsk Distr., Rostov Area, Russia); AT - personal collection of Andrei V. Tanasevitch (Moscow, Russia); CD - personal collection of Ch. DeelemanReinhold (Ossendrecht, the Netherlands); ISEA — Institute of Animal Systematics and Ecology, Siberian Branch, Russian Academy of Sciences (Novosibirsk, Russia, curator G.N. Azarkina); IZBA - Institute of Zoology, National Academy of Sciences (Baku, Azerbaijan); MMUE Manchester Museum, University of Manchester (UK, curator D.V. Logunov); MHNG - Muséum d'Histoire Naturelle, Genève (Suisse, curator P. Schwendinger); NHMB Natural History Museum, Budapest (Hungary, curator L. Dányi); NMP - National Museum, Praha (Czech Republic, curator P. Dolejš); PSU - Department of Invertebrate Zoology, Perm State University (Russia, curator S.L. Esyunin); SIZK - Schmalhausen Institute of Zoology, National Academy of Science, Kiev, Ukraine (curator K.V. Evtushenko); SMF - Senckenberg Museum (Frankfurt am Main, Germany, curator P. Jäger); TNU - Department of Invertebrate Zoology, Taurida National Univerisity, the Crimea (Simferopol, Russia, curator M.M. Kovblyuk), YM - personal collection of Yuri M. Marusik (Magadan, Russia and Turku, Finland); ZIN - Zoological Institute, the Russian Academy of Sciences (St. Petersburg, Russia, curator V.A. Krivokhatsky); ZMMU - Zoological Museum, Moscow State University (Moscow, Russia, curator K.G. Mikhailov); ZMUT - Zoological Museum, University of Turku (Finland, curator S. Koponen). Whereabouts of other types, except those that are deposited in the ZMMU, is given on the basis of original descriptions and WSC [2019]. In the ZMMU, museum accession numbers for Aranei are indexed with 'Ta' which is put at the beginning of museum labels. Labels are transcribed literally, with mistakes being indicated in comments.

The following translations of the administrative units are used hereinafter: Area for "область, oblast", District for "район, rayon", Province for "край, kray". The nomenclature mainly follows WSC [2019].

\section{albocinctus Kroneberg, 1875, Attus}

Kroneberg, 1875: 49-50, tab. V, fig. 36.

Ta-1035. Syntype +, Туркестанская Ученая Экспедиция Императорского Общества Любителей Естествознания. Федченко \{Turkestan Scientific Expedition by the Imperator Society for Friends of Natural Sciences. A.P. Fedchenko\}. 24. Шагимардан \{Shagimardan\}.

Ta-1041. Syntypes $1 \sigma^{7}$ (without palps), 3 +, 1 inad., Туркестанская Ученая Экспедиция Императорского Общества Любителей Естествознания. Федченко \{Turkestan Scientific Expedition by the Imperator Society for Friends of Natural Sciences. A.P. Fedchenko\}. 18. Самарканд \{Samarkand\}.

Тa-1043. Syntype ㅇ, Туркестанская Ученая Экспедиция Императорского Общества Любителей Естествознания. Федченко \{Turkestan Scientific Expedition by the Imperator Society for Friends of Natural Sciences. A.P. Fedchenko\}. 17. Ходжадук \{Khodzhaduk\}.

Original labels are "Attus n.sp." (Ta-1043) and "Attus sp." (Ta-1035, Ta-1041). Specimens are identified as the types by A.B. Nenilin in 1980 (pers. comm.) on the basis of the original description.

The types are kept in ZMMU only.
Current status. Pseudomogrus albocinctus (Kroneberg, 1875) (Salticidae).

amurensis Eskov et Marusik, 1992, Centromerus

Eskov, Marusik, 1992: 35, fig. 1a-c.

Тa-5242. Holotype $\sigma^{7}$, Хабаровский край, Большехехцирский заповедник, 60-й квартал, h 600-700 м, елово-пихтовый лес \{Khabarovsk Province, Bolshekhekhtsyrsky Reserve, compartment 60, 600-700 m a.s.l., spruce-fir forest $\}$, 9.VI.1987, собр. Д.В. Логунов \{D.V. Logunov\}.

Ta-5243. Paratype + , Хабаровский край, Большехехцирский заповедник, 60-й квартал, h 600-700 м, елово-пихтовый лес $\{$ Khabarovsk Province, Bolshekhekhtsyrsky Reserve, compartment 60, 600-700 m a.s.1., spruce-fir forest\}, 9.VI.1987, собр. Д.В. Логунов \{D.V. Logunov\}.

Ta-5244. Paratype +, Хабаровский край, Бойцово (12 км СВ Бикина), березово-дубово-тополевый лес \{Khabarovsk Area, Boitsovo (12 km NE of Bikin), birch-oak-poplar forest $\}, 26 . V-$ 4.VI.1991, собр. С.И. Головач \{S.I. Golovatch\}.

Ta-5245. Paratypes 2 우, Хабаровский край, Ульчский p-н, окр. с. Софийское, Скалистый хр. (гора Шаман), ельникзеленомошник, 350 м, подстилка \{Khabarovsk Province, Ul'cha Distr., nr. Sofiyskoe, Skalisty Mt. Range (Shaman Mt.), spruce forest with Hyloconium, Dicranum, Rhytidiadelphus, $350 \mathrm{~m}$ a.s.l., litter\}, VII.1990, собр. Г.Н. Ганин \{G.N. Ganin\}.

Ta-5246. Paratypes 3 웅, Приморье, Чугуевский p-н, p. Правая Соколовка (басс. p. Уссури), ельник \{Primorie [= Maritime Prov.], Chuguevka Distr., Pravaya Sokolovka River (Ussuri River Basin), spruce forest\}, 28.VIII.1974, собр. Г.Ф. Курчева \{G.F. Kurcheva\}.

Other types are kept in ISEA.

Current status. Centromerus amurensis Eskov et Marusik, 1992 (Linyphiidae).

amurensis Eskov, 1992, Ceratinops (Asiceratinops)

Eskov, 1992: 156, figs 9-15.

Тa-6182. Holotype $\sigma^{7}$, Хабаровский край, Нанайский p-н, p. Амур, Славянка, Славянский о-в, вейниковый луг \{Khabarovsk Area, Nanaysky Distr., Amur River, Slavyanka, Slavyansky Isl., Calamagrostris meadow\}, 7.V.1989, собр. Д.К. Куренщиков \{D.K. Kurenshchikov\}.

Ta-6183. Paratype + , Хабаровский край, Нанайский p-н, p. Амур, Славянка, Славянский о-в, вейниковый луг \{Khabarovsk Area, Nanaysky Distr., Amur River, Slavyanka, Slavyansky Isl., Calamagrostris meadow\}, 7.V.1989, собр. Д.К. Куренщиков \{D.K. Kurenshchikov\}.

Ta-6184. Paratypes 1 Ơ $^{7}, 2$ 우, Хабаровский край, Нанайский p-н, p. Амур, Славянка, Славянский о-в, вейник \{Khabarovsk Area, Nanaysky Distr., Amur River, Slavyanka, Slavyansky Isl., Calamagrostris\}, 26-28.V.1986, Н.А. Рябинин \{N.A. Ryabinin\}.

Та-6185. Paratype + , <Хабаровский край, > Большехехцирский запов. \{Khabarovsk Area, Bolshekhekhtsirsky Reserve\}, VI.1987, собр. Д.В. Логунов \{D.V. Logunov\}

Та-6186. Paratype $\sigma^{7}$, Приморье, Хасан \{Primorie [= Maritime Prov.], Khasan\}, 7.VI.1973, собр. Г.Ф. Курчева \{G.F. Kurcheva\}.

The types are kept in ZMMU only.

Original label for Ta-6182 refers to the name "Asiceratinops amurensis".

Current status. Asiceratinops amurensis Eskov, 1992 (Linyphiidae).

\section{baculum Tanasevitch, 2014, Batueta}

Tanasevitch, 2014: 401, figs 29-34.

Ta-8030. Paratype $0^{7}$, Thailand: Chiang Mai Province, Chiang Dao District, Doi Chiang Dao, 510 m, pitfall traps, 25.10-23.11. 1990, leg. P. Schwendinger.

Other types (holotype, paratypes) are kept in MHNG.

The species was described from the males only. In the original label, the species name "bacula" is indicated. 
Current status. Batueta baculum Tanasevitch, 2014 (Linyphiidae).

baskuntchakensis Ponomarev et Belosludtsev in Ponomarev, Belosludtsev et Dvadnenko, 2008, Bogdocosa

Ponomarev et al., 2008: 164, figs 1-6.

Та-6899. Holotype О', Россия, Астраханская обл., БогдинскоБаскунчакский запов., у водоёма \{Russia, Astrakhan Area, Bogdo-Baskunchak Reserve, nr. waterbody\}, 7-10.06.2005, E.A. Белослудцев \{Е.A. Belosludtsev\}.

Ta-6900. Paratypes $2 \sigma^{7} \sigma^{7}, 1$, Россия, Астраханская обл. Богдинско-Баскунчакский запов., у водоёма \{Russia, Astrakhan Area, Bogdo-Baskunchak Reserve, nr. waterbody\}, 7-10.06.2005, Е.А. Белослудцев \{Е.A. Belosludtsev\}.

Other types are kept in AP.

Current status. Synonymized with Bogdocosa kronebergi (Andreeva, 1976) (Lycosidae) [Esyunin, Ponomarev, 2018].

\section{caucasicus Tanasevitch, 1987, Asthenargus}

Tanasevitch, 1987: 338-340, figs 74-80.

Ta-4468. Holotype $\sigma^{7}$, USSR, Caucasus Major, $<$ Georgia, $>$ Kazbegi, 2000 m, in forests of Betula \& Pinus, in meadows, litter \& under stones, 2-6.VI.1982, собр. С.И. Головач \{S.I. Golovatch $\}$.

Ta-4469. Paratype 9 , Caucasus Major, $<$ Georgia, $>$ Kazbegi, $2000 \mathrm{~m}$, in forests of Betula \& Pinus, in meadows, litter \& under stones, 2-6.VI.1982, собр. С.И. Головач \{S.I. Golovatch\}.

Ta-4470. Paratypes $1 \sigma^{\top}, 2$ 우, USSR, N. Caucasus, Dagestan, Sergokala distr., near village Degva, oak forest on slope, litter, 9.VI.1982, собр. С.И. Головач \{S.I. Golovatch\}.

The types are kept in ZMMU only.

Current status. Asthenargus caucasicus Tanasevitch, 1987 (Linyphiidae).

\section{caucasicus Tanasevitch, 1990, Bolyphantes}

Tanasevitch, 1990: 10-11, fig. 2(1-5)

Тa-7917. Holotype $\sigma^{7}$, Ц-5. Сев. Осетия, Цейский хр., Ю склон 30-45 $(3-4$ км к В от с. Цей), выс. 2550 м, крупнозлаковое высокотравье верхней границы леса (среди парковых сосняков) \{N Ossetia, Tsey Mt. Range, S slope $30-45^{\circ}(3-4 \mathrm{~km} \mathrm{E}$ of Tsey), $2550 \mathrm{~m}$ a.s.l., at the timberline of tall gramineous grassland (among park-like pine forests)\}, 10-28.IV.1985, банки \{pitfall traps\}, С.К. Алексеев \{S.K. Alekseev\}.

Та-7918. Paratype + , Ц-10. Сев. Осетия, Цейский хр., 5 км В с. Цей, Ю склон 5-7, выс. 1350 м, разнотравный луг лесного пояса, используемый под выпас, среди сосняков \{N Ossetia, Tsey Mt. Range, $5 \mathrm{~km}$ E of Tsey, S slope $5-7^{\circ}, 1350 \mathrm{~m}$ a.s.1., multiherbaceous meadow in forest belt used for grazing, within pine forests\}, 8.VI-21.VII.1985, банки \{pitfall traps\}, С.К. Алексеев $\{$ S.K. Alekseev $\}$.

Та-7919. Paratype ণొ, В-2. Сев. Осетия, басс. p. Ардон, Боковой хр., левый борт Касарского ущ., уроч. Уилца (7 км выше пос. Бурон), полидоминантный сенокосный луг лесного пояса, ВЮВ экспозиция 2-5 $5^{\circ}$ N Ossetia, Ardon River Basin, Bokovoi Mt. Range, left slope of Kasar Canyon, Uiltsa (7 km upper to Buron), multidominant meadow of hay in the forest belt, ESE

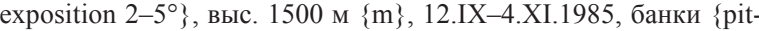
fall traps $\},$ С.К. Алексеев \{S.K. Alekseev\}.

The types are kept in ZMMU only.

Current status. Bolephthyphantes caucasicus (Tanasevitch, 1990) (Linyphiidae).

\section{cephalotus Tanasevitch, 1987, Bisetifer}

Tanasevitch, 1987: 342-343, figs 81-87.

Ta-4471. Holotype $\sigma^{7}$, Краснодарский край, Туапсинский район, 15 км к ЮВ от пос. Новомихайловский, Псебе, листопадный лес, под камнями, в гнилых колодах \{Krasnodar Prov., Tuapse Distr., 15 km SE of Novomikhailovskiy, Psebe, deciduous forest, under stones, in logs\}, 29.X.1981, собр. С.И. Головач \{S.I. Golovatch\}.

Тa-4472. Paratype $\sigma^{7}$, Краснодарский край, Туапсинский район, 15 км к ЮВ от пос. Новомихайловский, Псебе, листопадный лес, под камнями, в гнилых колодах \{Krasnodar Prov., Tuapse Distr., $15 \mathrm{~km}$ SE of Novomikhailovskiy, Psebe, deciduous forest, under stones, in $\operatorname{logs}\}, 29 . X .1981$, собр. С.И. Головач \{S.I. Golovatch .

The types are kept in ZMMU only.

Three more paratypes (Ta-4473-4475) were moved to the type series of Bisetifer gruzin Tanasevitch, Ponomarev et Chumachenko, 2015.

Current status. Bisetifer cephalotus Tanasevitch, 1987 (Linyphiidae). See also Tanasevitch et al. [2015].

\section{distichoides Tanasevitch, 2000, Bolyphantes}

Tanasevitch, 2000: 249, figs 24-27.

Ta-7829. Paratype + , W-Altai, $10 \mathrm{~km} \mathrm{~S}$ of Leninogorsk, 1700 $\mathrm{m}$, spring in Pinus-Larix forest, 30-31.V.1996, R.Y $<\mathrm{u}>$. Dudko.

The holotype + is kept in ISEA

In the original label, the name Lepthyphantes distichoides is given.

Current status. Bolyphantes distichoides Tanasevitch, 2000 (Linyphiidae).

\section{edentulus Tanasevitch, 1989, Asthenargus}

Tanasevitch, 1989: 127, figs 117-121.

Ta-5440. Holotype $\sigma^{7},<$ Киргизия,> Тянь-Шань, ТерскейАлатау, р. Чон-Кызыл-су, Карабаткак, ельник, во мху и подстилке \{Kirghizia, Tien-Shang $<$ Mts. $>$, Terskey-Alatau $<$ Mts. $>$, Chon-Kyzyl-Su River, Karabatkak, spruce forest, in moss and litter\}, 2600 м $\{\mathrm{m}\}, 2$. IX.1983, собр. А.Б. Рывкин \{А.В. Ryvkin\}.

Та-5441. Paratypes 9 우, <Киргизия,> Тянь-Шань, ТерскейАлатау, р. Чон-Кызыл-су, Карабаткак, ельник, во мху и подстилке \{Kirghizia, Tien-Shang $<$ Mts. $>$, Terskey-Alatau $<$ Mts. $>$, Chon-Kyzyl-Su River, Karabatkak, spruce forest, in moss and litter\}, 2600 м $\{\mathrm{m}\}$, 2.IX.1983, собр. А.Б. Рывкин \{А.В. Ryvkin\}.

Ta-5442. Paratypes 1 ऽ’, 1 , Киргизия, Киргизский хр., 30 км Ю Фрунзе, ур. Ала-Арча \{Kirghizia, Kirghizsky Mt. Range, $30 \mathrm{~km} \mathrm{~S}$ of Frunze [now Bishkek], Ala-Archa $\}, 1600 \mathrm{M}\{\mathrm{m}\}$, 28.IV.1983, собр. С.В. Овчинников \{S.V. Ovchinnikov\}.

Ta-5443. Paratypes 2 ㅇ, Киргизия, хр. Терскей-Алатоо, 30 км Ю Покровки, Айлама, ельник \{Kirghizia, Terskei-Alatoo Mt. Range, $30 \mathrm{~km} \mathrm{~S}$ of Pokrovka, Ailama, spruce forest $\}, 2800 \mathrm{~m}\{\mathrm{~m}\}$, 22.VII.1984, собр. Н.В. Турцева \{N.V. Turtseva\}.

Та-5444. Paratypes 2 о⿱ , КазССР, Алма-Атинская обл., АлмаАтинский запов. \{Kazakhstan, Alma-Ata [now Almaty] Area, Alma-Ata Reserve $\}$, h 1600-1800 м $\{\mathrm{m}\}$, подстилка \{litter\}, 12.IX.1983, собр. Ю.М. Марусик \{Yu.M. Marusik\}.

Other types are kept in SMF.

Current status. Asthenargus edentulus Tanasevitch, 1989 (Linyphiidae).

\section{elburzensis Tanasevitch, 2009, Bolyphantes}

Tanasevitch, 2009: 387-389, figs 3, 17-26.

Ta-7839. Paratypes $2 \sigma^{\top} \sigma^{\top}, 2$ 우, Iran, Tehran, Shemshak, $<2600$ m a.s.1.,> 27.8.1973, A. Senglet.

Other types (holotype, paratypes) are kept in $\mathrm{MHNG}$

Current status. Bolyphantes elburzensis Tanasevitch, 2009 (Linyphiidae).

\section{ephthalitus Fet, 1993, Cedicus}

Fet, 1993: 70-71, fig. 1.

Та-4009. Holotype $\sigma^{7},<$ Туркмения,> Ю3 Копетдаг, верховья ущ. Айдере, 1200 м, у воды, в хвоще \{Turkmenistan, SW Kopedagh $<$ Mts. $>$, Aidere Canyon upper part, $1200 \mathrm{~m}$ a.s.l., nr. water, in horsetail\}, 11.V-10.VI.1979, собр. В.Я. Фет \{V.Ya. Fet\}.

Та-4010. Paratype $\sigma^{7},<$ Туркмения, > Ю3 Копетдаг, верховья ущ. Айдере, 1200 м, у воды, в хвоще \{Turkmenistan, SW Kope- 
dagh $<$ Mts. $>$, Aidere Canyon upper part, $1200 \mathrm{~m}$ a.s.l., nr. water, in horsetail\}, 11.V-10.VI.1979, собр. В.Я. Фет \{V.Ya. Fet\}.

Ta-4011. Paratype + , <Туркмения,> Ю3 Копетдаг, Айдере \{Turkmenistan, SW Kopedagh <Mts.>, Aidere\}, IV.1975, экспед. ИЭМЭЖ <AН CCСР $>$ \{expedition of IEMEZh [= Institute of Evolutionary Morphology and Ecology, now Institute for Ecology and Evolution] AN SSSR

Та-4012. Paratype O', <Туркмения,> Ю3 Копетдаг, Айдере, луг из Elytrigia repens \{Turkmenistan, SW Kopedagh $<$ Mts. $>$, Aidere, Elytrigia repens meadow \}, 20-27.IX.1978, собр. В.Я. Фет $\{$ V.Ya. Fet .

Та-4013. Paratype $\sigma^{7},<$ Туркмения,> Ю3 Копетдаг, Айдере, под деревом грецкого ореха \{Turkmenistan, SW Kopedagh $<$ Mts.>, Aidere, under walnut tree\}, 11-18.III.1979, собр. В.Я Фет $\{$ V.Ya. Fet\}.

Та-4014. Paratype + , <Туркмения,> Ю3 Копетдаг, г. Хасар, 1600 м н.у.м., в степи из Festuca valesiana \{Turkmenistan, SW Kopedagh $<$ Mts. $>$, Khasar Mt., 1600 m a.s.1., in Festuca valesiana steppe\}, 19.IV.1979, собр. В.Я. Фет \{V.Ya. Fet\}.

Та-4015. Paratypes 2 ㅇ, <туркмения,> Ю3 Копетдаг, СюнтХасардагский запов., г. Хасар \{Turkmenistan, SW Kopedagh $<$ Mts. $>$, Syunt-Khasardagh Reserve, Khasar Mt.\}, 1600 м H.y.м. \{m a.s.1.\}, 4-8.VI.1982, собр.Н.C. Устинова \{N.S. Ustinova\}.

The types are kept in ZMMU only.

Current status. Paracedicus ephthalitus (Fet, 1993) (Cybaeidae).

galotshkae Evtushenko, 1993, Carpathonesticus

Evtushenko, 1993: 61-62, fig. 1a-c.

Тa-4874. Paratype $\sigma^{7}$, Украина, Закарпатская обл., Раховский p-н, с. Деловое, пещера Черемшина, 30 м вглубь от входа \{Ukraine, Zakarpatskaya Area, Rakhov Distr., Dellvoye, Cheremshina Cave, $30 \mathrm{~m}$ of the mouth\}, 10.IV.1990, собр. Р. Варгович $\{$ R. Vargovich $\}$. SIZK.

Other types (holotype male, paratype female) are kept in

Current status. Carpathonesticus galotshkae Evtushenko, 1993 (Nesticidae).

\section{gennadii Fet, 1993, Cedicus}

Fet, 1993: 71-72, fig. 2.

Ta-4028. Holotype О', Туркмения, Ц. Копетдаг, ущ. Куртусу \{Turkmenistan, Central Kopetdagh $<$ Mts. $>$, Kurtusu Canyon\}, 1522.III.1980, собр. Г.Т. Кузнецов \{G.T. Kuznetsov\}.

Та-4019. Paratypes 3 оя, Туркмения, Ц. Копетдаг, Куругаудан \{Turkmenistan, Central Kopetdagh $<$ Mts. $>$, Kurugaudan\}, 19-28.III.1980, собр. Г.Т. Кузнецов \{G.T. Kuznetsov\}.

Та-4020. Paratypes 1 ๙ , 1 क, Туркмения, Ю3 Копетдаг, Айдере \{Turkmenistan, SW Kopedagh <Mts.>, Aidere\}, IV.1975 экспед. ИЭМЭЖ <АН СССР $>$ \{expedition of IEMEZh [= Institute of Evolutionary Morphology and Ecology, now Institute for Ecology and Evolution] AN SSSR

Ta-4022. Paratype $\sigma^{7}$, C3 Туркмения, плато Туакыр, хр. Кафисгем \{NW Turkmenistan, Tuakyr Plateau, Kafisghem Mt. Range $\}, 500$ м \{m\}, 7.XI.1982, <собр. В.Я. Фет> \{V.Ya. Fet\}.

Та-4029. Paratypes $8 \sigma^{7} \sigma^{7}$, Туркмения, Ц. Копетдаг, ущ. Куртусу \{Turkmenistan, Central Kopetdagh $<$ Mts. $>$, Kurtusu Canyon\}, 15-22.III.1980, собр. Г.Т. Кузнецов \{G.T. Kuznetsov\}.

The types are kept in ZMMU only.

Collection numbers Ta-4016-4018, 4021 indicated in the original descriptions are missing in ZMMU collection.

Current status. Paracedicus gennadii (Fet, 1993) (Cybaeidae).

gruzin Tanasevitch, Ponomarev et Chumachenko, 2015, Bisetifer

Tanasevitch et al., 2015: 447-450, figs 4-6, 19-31.

Ta-7747. Holotype $\sigma^{7}$, Georgia, Caucasus, Saguramo Nature Reserve, NE of Mtskheta, Zeduzeni, 1100-1200 m a.s.1., 20.V.1987, leg. S. $<$ I. $>$ Golovatch \& K. $<$ Yu. $>$ Eskov.
Ta-7748. Paratypes $1 \sigma^{7}, 4$ 우, Georgia, Caucasus, Saguramo Nature Reserve, NE of Mtskheta, Zeduzeni, 1100-1200 m a.s.1., 20.V.1987, leg. S. $<$ I. $>$ Golovatch \& K. $<$ Yu. $>$ Eskov.

Ta-7749. Paratypes 2 오, Georgia, Caucasus, $\mathrm{N}$ of Kvirili, 700-750 m, Fagus, Carpinus, Quercus, etc. forest, litter and under bark, 4.V.1987, leg. S. $<$ I. $>$ Golovatch \& K. $<$ Yu. $>$ Eskov.

Тa-4473. Paratype 9 , Грузия, Лагодехский заповедник, лес из бука, ясеня, клена и др., подстилка, колоды, под камнями \{Georgia, Lagodekhi Reserve, Fagus, Fraxinus, Acer, etc. Forest, litter, logs, under stones $\}, 600-700$ м $\{\mathrm{m}\}$, 5-6.V.1983, собр. С.И. Головач $\{$ S.I. Golovatch\}.

Ta-4474. Paratype 9 , Грузия, Аджария, Хульский район, 3 км к 3 от дер. Даниспараули, листопадный лес, подстилка \{Georgia, Adzharia, Khulo Distr., $3 \mathrm{~km}$ W of Danisparauli, deciduous forest, litter\}, 10.X.1981, собр. С.И. Головач \{S.I. Golovatch\}.

Ta-4475. Paratypes $1 \sigma^{7}, 1$, Грузия, Амбролаурский район, Никорцминда, смешанный пихтово-листопадный лес, подстилка \{Georia, Ambrolauri Distr., Nikortsminda, mixed fir-deciduous forest, litter\}, 24.X.1981, собр. С.И. Головач \{S.I. Golovatch\}.

The types are kept in ZMMU only.

Three paratypes (Ta-4473-4475) were moved from the original type series of $B$. cephalotus.

Current status. Bisetifer gruzin Tanasevitch, Ponomarev et Chumachenko, 2015 (Linyphiidae).

\section{hypoarctica Eskov, 1988, Bishopiana}

Eskov, 1988: 679-680, fig. 1(1-5).

Ta-5057. Holotype $\sigma^{7},<$ Красноярский край>, пл. Путорана, о3. Аян, р. Капчуг, каменистое русло временного водотока, луговины на сеточках под камнями \{Krasnoyarsk Prov., Putorana Plateau, Ayan Lake, Kapchug River, temporary stream bed, meadow, under stones $\}$, 6.VI.1983, собр. К.Ю. Еськов $\{$ К.Yu. Eskov

Ta-5058. Paratype + , <Красноярский край>, пл. Путорана, o3. Аян, p. Капчуг, каменистое русло временного водотока, луговины на сеточках под камнями \{Krasnoyarsk Prov., Putorana Plateau, Ayan Lake, Kapchug River, temporary stream bed, meadow, under stones\}, 6.VI.1983, собр. К.Ю. Еськов \{К.Yu. Eskov\}.

Тa-5059. Paratypes $2 \sigma^{\top} \sigma^{7}, 15$ 우, <Красноярский край>, пл. Путорана, оз. Аян, р. Капчуг, каменистое русло временного водотока, луговины на сеточках под камнями \{Krasnoyarsk Prov., Putorana Plateau, Ayan Lake, Kapchug River, temporary stream bed, meadow, under stones\}, 6.VI.1983, собр. К.Ю. Еськов \{К.Yu. Eskov\}.

Ta-5060. Paratype + , <Красноярский край>, пл. Путорана, о3. Аян, p. Капчуг, субальпика, лиственничная редина, под камнями \{Krasnoyarsk Prov., Putorana Plateau, Ayan Lake, Kapchug River, subalpine zone, Larix sparse stand, under stones\}, 9.VI.1983, собр. К.Ю. Еськов \{К.Yu. Eskov\}.

Та-5061. Paratypes 1 フ , 3 के, <Магаданская обл.>, верх. Колымы, р. Детрин, 56 км от устья, руч. Вакханка, ленточный ивняк \{Magadan Area, upper flow of Kolyma River, Detrin River, $56 \mathrm{~km}$ of its mouth, Vakkhanka Stream, valley willow stand, 14.VIII.1983, собр. Ю.М. Марусик \{Yu.M. Marusik\}.

Other types are kept in ISEA.

Current status. Bishopiana hypoarctica Eskov, 1988 (Linyphiidae).

hyrcanica Guseinov, Marusik et Koponen, 2005,

\section{Azerithonica}

Guseinov et al., 2005: 159-164, figs 26-36, 111-113.

Ta-7511. Holotype $\sigma^{7}$, SE Azerbaijan, Lenkoran Distr., env. of Avrora Vill., 21.05.2003, E.F. Guseinov.

Ta-7512. Paratypes 2 + , SE Azerbaijan, Astara Distr., env. of Khamosham Vill., 26.08.1995, E.F. Guseinov.

Ta-7513. Paratype + , SE Azerbaijan, Lenkoran Distr., env. of Avrora Vill., 27.04.2001, E.F. Guseinov.

Ta-7514. Paratype + , SE Azerbaijan, Astara Distr., env. of Istisu Vill., 25.04.2001, H. Aliev.

Ta-7515. Paratypes 1 $\sigma^{7}, 2$ 우, SE Azerbaijan, Lenkoran Distr., env. of Apo Vill., 28.05.2003, H. Aliev. 
Ta-7516. Paratypes $4 \sigma^{\top} \sigma^{\top}, 4$ o 9 , SE Azerbaijan, Lenkoran area, Hyrcan Reserve, near dam, $38^{\circ} 38^{\prime} \mathrm{N}, 48^{\circ} 47^{\prime} \mathrm{E}, 28.05 .2003$ $\mathrm{Y}<\mathrm{u}>$.M. Marusik.

Ta-7517. Paratype $\sigma^{7}$, SE Azerbaijan, Lenkoran Distr., env. of Apo Vill., 28.05.2003, $\mathrm{Y}<\mathrm{u}>$.M. Marusik.

Ta-7518. Paratypes $2 \sigma^{\top} \sigma^{\top}, 2$ 0 , SE Azerbaijan, Lenkoran Distr., Hyrcan Reserve, 23.05.2003, E.F. Guseinov.

Other types are kept in IZBA, SMF, YM and ZMUT.

Current status. Azerithonica hyrcanica Guseinov, Marusik et Koponen, 2005 (Agelenidae).

\section{indexoides Tanasevitch, 1989, Bolyphantes}

Tanasevitch, 1989: 94-95, figs 19-23.

Тa-5445. Holotype $\sigma^{7}$, Киргизия, Тянь-Шань, Ферганский хр., окр. п. Яродар \{Kirghizia, Tien-Shang $<$ Mts.>, Ferghana Mt Range, env. of Yarodar\}, VIII-X.1984, собр. С.Л. Зонштейн \{S.L. Zonstein .

Та-5446. Paratypes $9 \sigma^{7}, 9$ о, Киргизия, Тянь-Шань, Ферганский хр., окр. п. Яродар \{Kirghizia, Tien-Shang <Mts.> Ferghana Mt. Range, env. of Yarodar\}, VIII-X.1984, собр. С.Л Зонштейн \{S.L. Zonstein .

Ta-5447. Paratypes 1 б , 3 ㅇ, Киргизия, Ферганский хр., окр. пос. Арсланбоб, сухой субальпийский луг, под камнями \{Kirghizia, Ferghana Mt. Range, env. of Arslanbob, dry subalpine meadow, under stones $\}, 2200$ м $\{\mathrm{m}\}, 1$. Х.1983, собр. К.Ю. Еськов $\{$ K.Yu. Eskov\}.

Ta-5448. Paratype + , Киргизия, Сары-Челекский запов., близ пос. Аркит, ореховый лес, подстилка \{Kirghizia, Sary-Chelek Reserve, nr. Arkit, walnut forest, litter $\}, 1500$ м $\{\mathrm{m}\}, 2 . V .1983$, С.Л. Зонштейн \{S.L. Zonstein\}.

Та-5449. Рaratype $\sigma^{7}$, Киргизия, окр. Фрунзе, с. Орто-Сай \{Kirghizia, env. of Frunze [now Bishkek], Orto-Say\}, 7.IV.1984, C.B. Овчинников $\{$ S.V. Ovchinnikov $\}$.

Ta-5450. Paratypes $3 \sigma^{7}, 8$ о, Узбекистан, Ташкентская обл., Угамский хр., окр. пос. Сиджак, Кайнарсай, 1400 м, ореховый лес, подстилка \{Uzbekistan, Tashkent Area, Ugamsky Mt. Range, env. of Sidzhak, Kainarsay, 1400 m a.s.l., walnut forest, litter\}, IV.1982, А.В. Танасевич \{A.V. Tanasevitch\}.

Та-5451. Paratype + , УзбССР, Чаткальский запов., БашКызыл-Сай, осоковое болотце у ручья \{Uzbekistan, Chatkalsky Reserve, Bash-Kyzyl-Say, sedge swamp near a stream\}, 19.IX.1983, К.Ю. Еськов $\{$ K.Yu. Eskov $\}$.

Ta-5452. Paratypes 1 フ, 1 q, Казахстан, Алма-Атинская обл., р. Б. Алмаатинка \{Kazakhstan, Alma-Ata [now Almaty] Area, Bolshaya Almaatinka River $\}, 2550$ м $\{\mathrm{m}\}$, 8.IX.1933, B.H Шнитников \{V.N. Shnitnikov\}.

Та-5453. Paratype $\sigma^{7},<$ Казахстан,> окр. Алма-Аты, Медео, 2000 м, подстилка в травостое на южном склоне \{Kazakhstan, env. of Alma-Ata [now Almaty], Medeo, $2000 \mathrm{~m}$ a.s.1., litter in a grassland at southern slope\}, 27.VIII.1983, Ю.М. Марусик \{Yu.M. Marusik\}.

Ta-5454. Paratype $\sigma^{\top},<$ Казахстан,> Джамбульская обл., окр. с. Георгиевка \{Kazakhstan, Dzhambul Area, env. of Georgievka\}, 26.X.1984, С.В. Овчинников \{S.V. Ovchinnikov\}.

Other types are kept in SMF.

Current status. Bolephthyphantes indexoides (Tanasevitch, 1989) (Linyphiidae).

\section{inexploratus Logunov, 1991, Bianor}

Logunov, 1991: 56-57, fig. 3 (1-3).

Та-4613. Holotype $0^{7}$, Тува, 5-7 км 3 г. Кызыл, пойма p. Енисей, окр. агробиостанции пединститута, 650-700 м над ур. моря, куртины чия \{Tuva, 5-7 km W of Kyzyl, Yenisei River floodplain, env. of pedagogical institute's agrobiostation, $650-700$ m a.s.1., Achnatherum thickets\}, 27.V.1990, собр. Д.В. Логунов \{D.V. Logunov\}.

Та-4612. Paratype O$^{7}$, Тува, 5-7 км 3 г. Кызыл, пойма $p$. Енисей, окр. агробиостанции пединститута, 650-700 м над ур. моря, куртины чия \{Tuva, 5-7 km W of Kyzyl, Yenisei River floodplain, env. of pedagogical institute's agrobiostation, 650-700 m a.s.1., Achnatherum thickets\}, 15-22.V.1990, собр. Д.В. Логунов $\{$ D.V. Logunov $\}$.
Other types are kept in ISEA and PSU.

Current status. Synonymized with Sibianor aurocinctus (Ohlert, 1865) (Salticidae) [Logunov, 2001].

\section{jeniseicus Eskov, 1979, Bathyphantes}

Eskov, 1979: 65-67, figs 1, 2, 15, 16.

Ta-3726. Paratypes $10^{\prime}, 1$ ㅇ. Енисей, Мирное $\left(62^{\circ} 20^{\prime}\right.$ $<$ с.ш.>), левый берег Енисея, тальники, в подстилке, состоящей из ветвей и прошлогодних стеблей крапивы и зонтичных \{Yenisei <River>, Mirnoe $\left(62^{\circ} 20^{\prime} \mathrm{N}\right)$, left bank of Yenisei, willow thickets, in litter consisting from branches and last year nettle and Apiaceae stems $\}$, 18.VI.1978, leg. К.Ю. Еськов \{K.Yu. Eskov\}.

Other types (holotype, paratypes) are kept in ZIN.

Current status. Bathyphantes jeniseicus Eskov, 1979 (Linyphiidae). See also Tanasevitch [2011].

\section{kolymensis Eskov, 1992, Ceratinops (Asiceratinops)}

Eskov, 1992: 156-159, figs 16-20.

Та-6187. Holotype $\sigma^{7},<$ Магаданская обл.,> верх. p. Колыма, окр. п. Сибит-Тыэллах, стац. Абориген, заболоченный лиственничник южного склона сопки \{Magadan Area, upper flow of Kolyma River, env. of Sibit-Tyellakh, Aborigen field station, swampy larch forest at the sopka [=hill] southern slope\}, 1-14.VI. 1983, собр. Ю.М. Марусик \{Yu.M. Marusik\}.

Та-6188. Paratype + , <Магаданская обл., > верх. p. Колыма, окр. п. Сибит-Тыэллах, стац. Абориген, заболоченный лиственничник южного склона сопки \{Magadan Area, upper flow of Kolyma River, env. of Sibit-Tyellakh, Aborigen field station, swampy larch forest at the sopka [=hill] southern slope\}, 1-14.VI. 1983, собр. Ю.М. Марусик \{Yu.M. Marusik\}.

Та-6189. Paratype О, $^{7}<$ Магаданская обл.,> верх. p. Колыма, окр. п. Сибит-Тыэллах, стац. Абориген, болото на берегу Колымы, ловчие банки \{Magadan Area, upper flow of Kolyma River, env. of Sibit-Tyellakh, Aborigen field station, swamp on Kolyma River bank, pitfall traps\}, 27.VI-7.VII.1983, собр. А.Д. Авершин \{A.D. Avershin\}.

Та-6190. Paratype + , $<$ Магаданская обл., > верх. р. Колыма, окр. п. Сибит-Тыэллах, стац. Абориген, лиственничник у пристани \{Magadan Area, upper flow of Kolyma River, env. of Sibit-Tyellakh, Aborigen field station, larch forest near a wharf\}, 17-27.VI.1983, собр. К.Ю. Еськов (?) \{K.Yu. Eskov (?)\}.

Та-6191. Paratype + , <Магаданская обл.,> верх. p. Колыма, окр. п. Сибит-Тыэллах, стац. Абориген, мох под камнем, склон сопки \{Magadan Area, upper flow of Kolyma River, env. of SibitTyellakh, Aborigen field station, moss under stone, sopka [=hill] slope\}, 29.VIII.1985, собр. Ю.М. Марусик \{Yu.M. Marusik\}.

Та-6192. Paratypes 1 O’, 6 우, <Магаданская обл.,> верх. p. Колыма, окр. п. Сибит-Тыэллах, стац. Абориген \{Magadan Area, upper flow of Kolyma River, env. of Sibit-Tyellakh, Aborigen field station\}, лето \{summer\} 1985, собр. Ю. Марусик \{Yu.M. Маrusik\}.

Ta-6193. Paratype + , <Магаданская обл.,> верх. р. Колыма, p. Детрин, 56 км от устья, руч. Вакханка, каменистая отмель у ручья \{Magadan Area, upper flow of Kolyma River, Detrin River, $56 \mathrm{~km}$ from the üouth, Vakkhanka Stream, stony shallow nr. a stream\}, 13.VIII.1984, собр. К.Ю. Еськов \{К.Yu. Eskov\}.

The types are kept in ZMMU only.

The original labels for Ta-6187, 6189, 6190, 6191, 6192 and 6193 refer to the name "Asiceratinops kolymensis".

$\mathrm{K}$.Yu. Eskov worked at the Aborigen field station in 1984. It is likely that the collecting year was incorrectly indicated for Ta-6190 as 1983 (see above).

Current status. Asiceratinops kolymensis Eskov, 1992 (Linyphiidae).

koponeni Marusik, Fomichev et Omelko, 2014, Ber-

\section{landina}

Marusik et al., 2014: 192-195, figs 30-37.

Ta-7774. Holotype $\sigma^{7}$, Mongolia, Omnogov Aimak, unknown locality, sand dune, 1.06.1997, Yu.M. Marusik. 
Other types are kept in NHMB.

Current status. Marusik, Fomichev et Omelko, 2014 (Gnaphosidae)

\section{kulsaryensis Ponomarev, 2007, Caspicosa}

Ponomarev, 2007: 93-94, figs 28-31.

Тa-6875. Holotype O" $^{7}$ Казахстан, Атырауская обл., от пос. Кульсары $<$ на $>26^{\circ} 80$ км \{Kazakhstan, Atyrau Area, $80 \mathrm{~km}$ from Kulsary by $\left.26^{\circ}\right\}, 5.06 .1987$, В. Романов \{V. Romanov\}.

Та-6876. Paratypes $10^{7}, 1$ ㅇ, Казахстан, Атырауская обл., от пос. Кульсары $<$ на $>26^{\circ} 80$ км \{Kazakhstan, Atyrau Area, 80 $\mathrm{km}$ from Kulsary by $\left.26^{\circ}\right\}, 5.06 .1987$, В. Романов \{V. Romanov\}. Other types are kept in AP.

Current status. Caspicosa kulsaryensis Ponomarev, 2007 (Lycosidae).

\section{nella}

kurenshchikovi Marusik et Gnelitsa, 2009, Cerati-

Marusik, Gnelitsa, 2009: 722-723, figs 1-10.

Ta-7408. Holotype $\sigma^{7}$, Russia, Khabarovsk Prov., environs of Khabarovsk, Bolshekhekhtsyrski Reserve, Klyuch Sosninskiy Kordon $\left(48^{\circ} 14^{\prime} \mathrm{N}, 134^{\circ} 47^{\prime} \mathrm{E}\right)$, broad leaved forest, ca. $400 \mathrm{~m}$, fallen tree, 8.06.1994, D.K. Kurenshchikov.

The species was described from the holotype only.

Current status. Ceratinella kurenshchikovi Marusik et Gnelitsa, 2009 (Linyphiidae).

\section{lamellaris Tanasevitch, 1990, Bolyphantes}

Tanasevitch, 1990: 11-13, fig. 3 (1-5).

Ta-7848. Holotype $\sigma^{7}$, Ц-10. Сев. Осетия, Цейский хр., 5 км В с. Цей, Ю склон 5-7 , выс. 1350 м, разнотравный луг лесного пояса, используемый под выпас, среди сосняков \{N Ossetia Tsey Mt. Range, $5 \mathrm{~km}$ E of Tsey, S slope 5-7, $1350 \mathrm{~m}$ a.s.1., multiherbaceous meadow in forest belt used for grazing, within pine forests\}, 29.IX-29.X.1985, банки \{pitfall traps\}, С.К. Алексеев $\{$ S.K. Alekseev $\}$

Та-7849. Paratype $\sigma^{7}$, Ц-10. Сев. Осетия, Цейский хр., 5 км В с. Цей, Ю склон 5-7, выс. 1350 м, разнотравный луг лесного пояса, используемый под выпас, среди сосняков \{N Ossetia, Tsey Mt. Range, $5 \mathrm{~km}$ E of Tsey, S slope 5-7 ${ }^{\circ}, 1350 \mathrm{~m}$ a.s.1., multiherbaceous meadow in forest belt used for grazing, within pine forests\}, 28.IX.1985, банки \{pitfall traps\}, С.К. Алексеев \{S.K. Alekseev\}.

Ta-7850. Paratypes $2 \bigcirc^{7} \sigma^{7}, 3$ ㅇ, Ц-10. Сев. Осетия, Цейский хр., 5 км В с. Цей, Ю склон 5-7, выс. 1350 м, разнотравный луг лесного пояса, используемый под выпас, среди сосняков $\left\{\mathrm{N}\right.$ Ossetia, Tsey Mt. Range, $5 \mathrm{~km}$ E of Tsey, S slope $5-7^{\circ}, 1350 \mathrm{~m}$ a.s.1., multiherbaceous meadow in forest belt used for grazing, within pine forests\}, 29.IX-29.X.1985, банки \{pitfall traps\}, С.К. Алексеев \{S.K. Alekseev\}.

Other types are kept in SMF.

Current status. Bolyphantes lamellaris Tanasevitch, 1990 (Linyphiidae).

\section{latens Logunov, 1991, Bianor}

Logunov, 1991: 54-56, fig. $3(5,6)$.

Та-4604. Holotype +, Тува, 5-7 км 3 г. Кызыл, пойма р. Енисей, агробиостанция пединститута, 650-700 м над ур. моря, мезофитный луг, в траве \{Tuva, 5-7 km W of Kyzyl, Yenisei River floodplain, env. of pedagogical institute's agrobiostation, 650-700 m a.s.1., mesophyte meadow, in grass \}, 23.VII.1989, coбp. Д.В. Логунов $\{$ D.V. Logunov $\}$.

The species was described from the holotype only.

Current status. Sibianor latens (Logunov, 1991) (Salticidae).

\section{logunovi Jäger, 2000, Cebrennus}

Jäger, 2000: 169-171, figs 7-16.

Ta-6424. Paratype O', Т<уркм> CCP, Репетек, на свет \{Turkmenistan, Repetek, on light\}, 5.V.1972, V.I. Kuznetsov.
Та-6425. Paratype $\sigma^{7}$, Репетек, Юго-Вост. Каракумы, Туркмения, на стене с жертвой \{Repetek, SE Karakumy <Desert>, Turkmenistan, on a wall, with a victim\}, 2.V.1982, В.А. Кривохатский \{V.A. Krivokhatsky\}.

Ta-6426. Paratypes 4 Oフ $^{7}$, ТСCP, Репетек, на свет \{Turkmenistan, Repetek, on light\}, 6.V.1972, V.I. Kuznetsov.

Ta-6427. Paratypes 4 оя, <Туркмения,> Репетек, на свет у дома \{Turkmenistan, Repetek, on light nr. house\}, 4.V.1972, V.I. Kuznetsov.

Ta-6428. Paratype $\sigma^{7}$, ТCCP, Репетек, на свет \{Turkmenistan, Repetek, on light\}, 3.V.1972, V.I. Kuznetsov.

Types have individual author's numbers: PJ1372 for Ta6424, PJ1373 for Ta-6425, PJ1374-1377 for Ta-6426, PJ1378-1381 for Ta-6427, PJ1383 for Ta-6428.

Other types are kept in ISEA and SMF.

Current status. Cebrennus logunovi Jäger, 2000 (Sparassidae).

\section{major Kroneberg, 1875, Caelotes}

Kroneberg, 1875: 15-16, tab. I, fig. 6.

Ta-3845. Lectotype + [designated here], Туркестанская Ученая Экспедиция Императорского Общества Любителей Естествознания. Федченко \{Turkestan Scientific Expedition by the Imperator Society for Friends of Natural Sciences. A.P. Fedchenko\}. Аучидагана \{Auchidagana\}. 2.VI

Ta-1058. Paralectotypes 9 juv., Туркестанская Ученая Экспедиция Императорского Общества Любителей Естествознания. Федченко \{Turkestan Scientific Expedition by the Imperator Society for Friends of Natural Sciences. A.P. Fedchenko\}. Аучидагана \{Auchidagana\}. 2.VI

Ta-1059. Paralectotype + , Туркестанская Ученая Экспедиция Императорского Общества Любителей Естествознания. Федченко \{Turkestan Scientific Expedition by the Imperator Society for Friends of Natural Sciences. A.P. Fedchenko\}. 15. Коканское ханство \{Kokan Khanate\}.

The lectotype was initially distinguished from the syntypes Ta-1058 by S.V. Ovchinnikov on 23 March 1984, but this taxonomic act has never been published.

The types are kept in ZMMU only.

Current status. Pireneitega major (Kroneberg, 1875) (Agelenidae).

\section{manytchensis Ponomarev, 2007, Caspicosa}

Ponomarev, 2007: 93, figs 24-27.

Та-6873. Holotype о, Россия, Ростовская обл., Орловский p-н, зап. «Ростовский», г. Лысая \{Russia, Rostov Area, Orlovsky Distr., Rostovsky Reserve, Lysaya Mt.\}, 12-16.05.2005, Ю.Г. Арзанов \{Yu.G. Arzanov\}.

Та-6874. Paratypes 2 ○’ $\sigma^{7} .2$ фо, Россия, Ростовская обл., Орловский р-н, зап. «Ростовский», Стариковский участок \{Russia, Rostov Area, Orlovsky Distr., Rostovsky Reserve, Starikovsky compartment\}, 7.05.2004, 3.Г. Пришутова \{Z.G. Prishutova\}.

Other types are kept in AP.

Current status. Caspicosa manytchensis Ponomarev, 2007 (Lycosidae).

\section{medius Oliger, 1999, Atypus}

Oliger, 1999: 201-203, figs 1-12.

Та-6230. Holotype $\sigma^{7}$, Приморье, Лазовский р-н, с. Киевка, дубрава на юж. склоне \{Primorie [=Maritime Prov.], Lazo Distr., Kievka, oak forest on southern slope\}, 24.VII.1975, собр. Т.И. Олигер \{T.I. Oliger\}.

Та-6231. Paratype $\sigma^{7}$, Приморский край, Уссурийский р-н, окр. дер. Кондратеновка (Каменушка) \{Maritime Prov., Ussuriysk Distr., env. of Kondratenovka (Kamenushka)\}, VII.1992, собр. И.А. Пилипенко \{I.A. Pilipenko\}.

The types are kept in ZMMU only.

Current status. Atypus medius Oliger, 1999 (Atypidae). 
nabozhenkoi Ponomarev et Tsvetkov, 2006, Ber-

\section{landina}

Ponomarev, Tsvetkov, 2006: 5, figs 1-2.

Та-6819. Holotype $\sigma^{7}$, Россия, Астраханская обл., Икраянинский р-н, окрестности ильменя Капитанский $\left(46^{\circ} 07^{\prime}\right.$ с.Ш., $47^{\circ} 42^{\prime}$ в.д.) \{Russia, Astrakhan Area, Ikrayaninsky Distr., env. of Kapitansky Ilmen' $\left.\left(46^{\circ} 07^{\prime} \mathrm{N}, 47^{\circ} 42^{\prime} \mathrm{E}\right)\right\}, 29.04 .2006$, leg. M.B. Набоженко \{M.V. Nabozhenko\}.

The species was described from the holotype only.

Current status. Berlandina nabozhenkoi Ponomarev et Tsvetkov, 2006 (Gnaphosidae).

nenilini Ponomarev et Tsvetkov, 2006, Berlandina Ponomarev, Tsvetkov, 2006: 7, fig. 3.

Та-6820. Holotype 9 , Казахстан, Атырауская обл., 10 км ЮВ пос. Махамбет, левобережье р. Урал, берег канала, густое разнотравье \{Kazakhstan, Atyrau Area, $10 \mathrm{~km}$ SE of Makhambet, left bank of Ural River, channel bank, dense multiherbaceous grassland\}, 17.06.1986, leg. A.В. Пономарёв \{A.V. Ponomarev\}.

The species was described from the holotype only.

Current status. Berlandina nenilini Ponomarev et Tsvetkov, 2006 (Gnaphosidae).

nurgush Tanasevitch et Esyunin, 2013, Centromerus

Tanasevitch, Esyunin, 2013: 257-259, figs 1-10.

Ta-7672. Holotype $\sigma^{7}$, Russia, Kirov Area, Nurgush Reserve, meadow, 17-24.VI.2011, leg. L. Tselishcheva.

Ta-7673. Paratypes 4 O $^{\top} 0^{\top}, 2$ 우, Russia, Kirov Area, Nurgush Reserve, meadow, 17-24.VI.2011, leg. L. Tselishcheva.

Ta-7674. Paratype $\sigma^{7}$, Russia, Kirov Area, Nurgush Reserve, meadow, 20-29.V.2011, leg. L. Tselishcheva.

Other types are kept in MHNG and PSU.

Current status. Centromerus nurgush Tanasevitch et Esyunin, 2013 (Linyphiidae).

\section{furcia}

oligerae Marusik, Omelko et Koponen, 2016, Bi-

Marusik et al., 2016: 77-81, figs 1-3, 6-9, 11-13, 23-25.

Ta-7807. Holotype + , Russia, Maritime Prov., Shkotovskii Dist., scree among coniferous forest near the stream, $43^{\circ} 11^{\prime} \mathrm{N}$, $132^{\circ} 43^{\prime}$ E, 22.06.2015, M.M. Omelko.

Ta-7808. Paratypes $1 \odot^{7}, 1 \sigma^{7}$ sbad, 8 우, Russia, Lazovskii Dist., Lazo Reserve, Syao-Changou gorge, debris $<,>$ under stone $<\mathrm{s}>$, mountain slope, 13.08.1981, T.I. Oliger.

Ta-7809. Paratype $\sigma^{7}$, Russia, Maritime Prov., Lazovskii Dist., Lazo Reserve, Sukhoi Klyuch gorge, open scree on S slope, upper part, under stones, 22.06.1981, T.I. Oliger.

Ta-7810. Paratypes 2 우, 09 Russia, Maritime Prov., south part, env. of Anisimovka Vill., $43^{\circ} 10^{\prime} \mathrm{N}, 132^{\circ} 46^{\prime} \mathrm{E}, 24-28.07 .1998$, $\mathrm{Y}<\mathrm{u}>$.M. Marusik.

Althouth in the original description [Marusik et al., 2016] other studied types were mentioned as being deposited in MMUE, actually they have never been placed there and their whereabouts is unknown (D.V. Logunov, pers. comm.).

Current status. Bifurcia oligerae Marusik, Omelko et Koponen, 2016 (Linyphiidae).

\section{orientalis Eskov, 1987, Ceraticelus}

Eskov, 1987: 1748-1750, fig. 1(1-4).

Ta-5150. Holotype $\sigma^{7}$, Амурская обл., Хинганский заповед., кордон Карапча, дубняк, подстилка \{Amurskaya Area, Khingan Reserve, Karapcha Kordon, oak forest, litter\}, 12.VIII.1983, coбp. Ю.М. Марусик \{Yu.M. Marusik\}.

Та-2445. Paratype ㅇ, Камчатка, окр. с. Ключи, кустарник, кошение \{Kamchatka, env. of Klyuchi, bushes, sweeping\}, 13.IX.1930, собр. В.И. Перелешина \{V.I. Pereleshina\}.

Та-5151. Paratypes 2 O’ $^{7}$, Амурск. обл., Хинганск. запов., Антоновское лесничество, дуб̆нк, подстилка \{Amurskaya Area,
Khingan Reserve, Antonovskoe Forestry, oak forest, litter\}, 2.VIII.1993, собр. Ю.М. Марусик \{Yu.M. Marusik\}.

Ta-5152. Paratype + , Еврейская АО, p. Амур, Пашково, дубняк, подстилка $\{$ Jewish Autonomous Region, Amur Area, Pashkovo, oak forest, litter\}, 5.VI.1978, собр. C.B. Tомс $\{$ S.V. Toms $\}$. Ta-5153. Paratypes 2 우, Хабаровский край, р. Амур, Славянка, березняк, подстилка \{Khabarovsk Prov., Amur River, Slavyanka, birch forest, litter\}, лето \{summer\} 1983, собр. Н.A. Рябинин \{N.A. Ryabinin\}.

The types are kept in ZMMU only.

The specimen from Ta-2445 was initially identified by V.I. Pereleshina (Sychevskaya) as Maso sundevalli (Westring, 1851).

Current status. Ceraticelus orientalis Eskov, 1987 (Linyphiidae).

ovtsharenkoi Marusik, Fomichev et Omelko, 2014,

\section{Berlandina}

Marusik et al., 2014: 195-197, figs 38-48.

Ta-7723. Paratype + , Mongolia, Khovd Aimag, $36 \mathrm{~km} \mathrm{SW}$ from Altai Village, Bodonchiyn-Gol River Valley $\left(45^{\circ} 45^{\prime} \mathrm{N}\right.$, $92^{\circ} 11^{\prime} \mathrm{E}$ ), stony desert, $1300 \mathrm{~m}, 7-8.05 .2012$, leg. Fomichev A.A. Other types are kept in ISEA and NHMB.

Current status. Berlandina ovtsharenkoi Marusik, Fomichev et Omelko, 2014 (Gnaphosidae).

pacificus Eskov et Marusik, 1992, Centromerus

Eskov, Marusik, 1992: 37-39, fig. 2d-f.

Та-5252. Holotype $\sigma^{7},<$ Магаданская обл., $>12$ км С Магадана, Снежная долина \{Magadan Area, $12 \mathrm{~km} \mathrm{~N}$ of Magadan, Snezhnaya Dolina\}, 12-14.IX.1990, собр. Ю.М. Марусик \{Yu.M. Marusik\}.

Ta-5253. Paratype + , $<$ Магаданская обл., $>12$ км С Магадана, Снежная долина \{Magadan Area, $12 \mathrm{~km} \mathrm{~N}$ of Magadan, Snezhnaya Dolina\}, 12-14.IX.1990, собр. Ю.М. Марусик \{Yu.M. Marusik\}.

Ta-5254. Paratype 9 , Магадан, Марчеканский п-ов [= п-ов Старицкого] \{Magadan, Staritsky Peninsula\}, 14.IX.1990, собр. Ю.М. Марусик \{Yu.M. Marusik\}.

Ta-5255. Paratype + , $<$ Магаданская обл., $>$ p. Дукча, 29 км C Магадана \{Magadan Area, Dukcha River, $29 \mathrm{~km} \mathrm{~N}$ of Magadan\}, 18.VI.1987, собр. Ю.М. Марусик \{Yu.M. Marusik\}.

Ta-5256. Paratypes $1 O^{\top}$ (without abdomen), $19,<$ Магаданская обл.,> верх. Колымы, окр. пос. Сибит-Тыэллах, стац. Абориген, ю. склон, брусничник, ловчие банки \{Magadan Area, upper flow of Kolyma River, env. of Sibit-Tyellakh, Aborigen field station\}, 26.V-5.VI.1983, собр С.П. Бухкало \{S.P. Bukhkalo\}.

Ta-5257. Paratype + , NE Siberia, $<$ Yakutia, $>5 \mathrm{~km}$ E of Yana River mouth, 24.VIII.1990, Ю.М. Марусик \{Yu.M. Marusik\}.

Ta-5258. Paratypes $3 \sigma^{7} \sigma^{7}$, Читинская обл., Сохондинский запов., слияние руч. Ларионова и р. Агуца, 1300 м, заросший курум \{Chita Area, Sokhondo Reserve, Larionova Stream and Agutsa River confluence, $1300 \mathrm{~m}$ a.s.1., kurum [= scree] overgrown with vegetation\}, 13.VI.1991, Д.В. Логунов \{D.V. Logunov\}.

Ta-5259. Paratype + , Амурск. обл., Хинганск. запов., корд. Карапча, дубняк, подст. $<$ илка > Amurskaya Area, Khingan Reserve, Karapcha Kordon, oak forest, litter\}, 21.VIII.1983, Ю.M. Марусик \{Yu.M. Marusik\}.

Тa-5260. Paratype О7, Хабаровский край, Большехехцирский запов. \{Khabarovsk Province, Bolshekhekhtsyrsky Reserve\}, VI.1987, собр. Д.В. Логунов \{D.V. Logunov\}.

Ta-5261. Paratypes 3 우, Хабаровский край, Большехехцирский запов., равнинный лес \{Khabarovsk Province, Bolshekhekhtsyrsky Reserve, plain forest $\}$, 13.VI.1987, Д.В. Логунов $\{$ D.V. Logunov\}.

Ta-5262. Paratype + , Амурск. обл., Хинганский запов., p. Карапча, хр. М. Хинган, 12 км на юг от п. Кундур, дубняк, подстилка \{Amurskaya Area, Khingan Reserve, Karapcha River, Malyi Khingan Mt. Range, oak forest, litter\}, VIII.1991, собр. Г.Н. Ганин \{G.N. Ganin\}.

Та-5263. Рaratype + , Хабаровск. край, Баджальский хр., p. Могда, елово-лиственничн. тайга \{Khabarovsk Area, Badzhal- 
sky Mt. Range, Mogda River, spruce-larch taiga $\}, 1000$ м $\{\mathrm{m}\}$, 13-14.VIII.1989, собр.Д.К. Куренщиков \{D.K. Kurenshchikov\}. Та-5264. Paratypes $1 \sigma^{7}, 1$, Приморье, Уссурийский заповедник, долинный лес \{Primorie [= Maritime Prov.], Ussuri Reserve, plain forest\}, 30.IX.1977, собр. Г.Ф. Курчева, Е.В. Михалёва \{G.F. Kurcheva, E.V. Mikhaljova\}.

Other types are kept in ISEA.

Current status. Centromerus pacificus Eskov et Marusik, 1992 (Linyphiidae).

\section{parthus Fet, 1993, Cedicus}

Fet, 1993: 72-73, fig. 4.

Ta-4023. Holotype Оॅ, Туркмения, Ц. Копетдаг, ущ. Фирюза \{Turkmenistan, Central Kopetdagh $<$ Mts. $>$, Firyuza Canyon\}, 16 23.X.1979, собр. Г.T. Кузнецов \{G.T. Kuznetsov\}.

Та-4024. Paratype ऽ’, Туркмения, Ц. Копетдаг, ущ. Б. Катранки (=Каранки) \{Turkmenistan, Central Kopetdagh <Mts.>, Bolshaya Katranki (=Karanki) Canyon\}, 9-16.IX.1978, собр. Г.T. Кузнецов \{G.T. Kuznetsov\}.

Та-4025. Paratype $\sigma^{7}$, Туркмения, Ц. Копетдаг, ущ. Каранки (=Б. Катранки) \{Turkmenistan, Central Kopetdagh $<$ Mts. $>$, Karank (= Bolshaya Katranki) Canyon $\}, 8-15 . I V .1980$, собр. Г.Т. Кузнецов \{G.T. Kuznetsov\}.

Та-4026. Paratype 9 , Туркмения, Ю3 Копетдаг, ущ. Айдере, сухой склон (Artemisieto-Festucetum), под камнем \{Turkmenistan, SW Kopedagh $<$ Mts. $>$, Aidere Canyon, dry slope (ArtemisietoFestucetum), under stone\}, 8.V.1979, собр. В.Я. Фет \{V.Ya. Fet\}.

Ta-4030. Paratypes $7 \sigma^{7} \sigma^{7}$, Туркмения, Ц. Копетдаг, ущ. Фирюза \{Turkmenistan, Central Kopetdagh $<$ Mts. $>$, Firyuza Canyon\}, 16-23.X.1979, собр. Г.Т. Кузнецов \{G.T. Kuznetsov\}.

The types are kept in ZMMU only.

In the original description, three males were indicated for Ta-4024, whereas actually the sample contains the paratype $\sigma^{\nearrow}$ only.

Current status. Cedicoides parthus (Fet, 1993) (Cybaeidae).

\section{punjabicus Logunov, 2001, Bianor}

Logunov, 2001: 244-247, figs 143-153.

Ta-6710. Paratype $\sigma^{\top}$, India, Punjab, Patiala City, University Campus, $30^{\circ} 21^{\prime} \mathrm{N}, 76^{\circ} 27^{\prime} \mathrm{E}, 3-8 . \mathrm{V} .1999$, coll. Yu. Marusik.

Other types are kept in ISEA and NMP.

Current status. Bianor punjabicus Logunov, 2001 (Salticidae).

\section{saraevi Ponomarev, 2008, Berlandina}

Ponomarev, 2008: 55-57, fig. 23-24.

Та-6850. Holotype $\sigma^{7}$, Казахстан, Атырауская обл., от пос. Кульсары $71^{\circ}$ - 65 км, плакор с белой полынью (Artemisia lercheana) и биюргуном (Anabasis ramosissima), ночью на свет $\left\{\right.$ Kazakhstan, Atyrau Area, 65 of Kulsary by $71^{\circ}$, flat interfluve with white wormwood (Artemisia lercheana) and Anabasis ramosissima, at night, on light\}, 16.05.1987, Ф.A. Сараев \{F.A. Saraev\}.

Та-6851. Paratype ơ, Казахстан, Атырауская обл., от пос. Кульсары $71^{\circ}-65$ км, плакор с белой полынью (Artemisia lercheana) и биюргуном (Anabasis ramosissima), ночью на свет \{Kazakhstan, Atyrau Area, 65 of Kulsary by $71^{\circ}$, flat interfluve with white wormwood (Artemisia lercheana) and Anabasis ramosissima, at night, on light\}, 16.05.1987, Ф.A. Сараeв \{F.A. Saraev\}.

Other types are kept in AP.

Current status. Berlandina saraevi Ponomarev, 2008 (Gnaphosidae).

\section{severtzovi Tanasevitch, 1989, Bolyphantes}

Tanasevitch, 1989: 95-96, figs 26-28.

Тa-5555. Holotype $\sigma^{7}$, Киргизия, предгорья Киргизского хр., с. Чон-Арык \{Kirghizia, piedmonts of Kirghizsky Mt. Range, Chon-Aryk $\}, 1100-1300$ м $\{\mathrm{m}\}, 27 . I V .1983$, собр. С.В. Овчинников $\{\mathrm{S} . \mathrm{V}$. Ovchinnikov\}.

Та-5556. Paratype +, Киргизия, окр. Фрунзе, предгорья Киргизского хр., с. Кок-Джар \{Kirghizia, env. of Frunze now
Bishkek], piedmonts of Kirghizsky Mt. Range, Kok-Dzhar\}, 10001300 м $\{\mathrm{m}\}, 16 . \mathrm{IV} .1983$, собр. С.В. Овчинников $\{\mathrm{S} . \mathrm{V}$. Ovchinnikov?.

Ta-5557. Paratype + , Киргизия, 2,5 км С Фрунзе, Чуйская долина \{Kirghizia, $2.5 \mathrm{~km} \mathrm{~N}$ of Frunze [now Bishkek], Chuiskaya Valley\}, 800-900 м \{m\}, 23.V.1979, собр. С.Л. Зонштейн \{S.L. Zonstein .

Та-5558. Paratype +, Киргизия, 20 км Ю Фрунзе, Киргизский хр., ущ. Малиновое \{Kirghizia, $20 \mathrm{~km} \mathrm{~S}$ of Frunze [now Bishkek], Kirghizsky Mt. Range, Malinovoe Canyon\}, 1700-2000 м $\{\mathrm{m}\}, 27 . \mathrm{VII} .1983$, собр. С.В. Овчинников $\{\mathrm{S} . \mathrm{V}$. Ovchinnikov\}.

Та-5559. Paratype 9 , Киргизия, хр. Кунгей Ала-Тоо, ущ. Чон-Урюкты \{Kirghizia, Kungei Alatoo Mt. Range, Chon-Uryukty Canyon $\}, 2100$ м $\{\mathrm{m}\}, 4$.VII.1985, собр. С.В. Овчинников \{S.V. Ovchinnikov\}.

Та-5560. Paratypes 2 фо, Ю. Казахстан, Сев. Тянь-Шань, Джамбульская обл., горы Киндыктас, пер. Курдай \{S Kazakhstan, N Tien-Shang <Mts. >, Dzhambul Area, Kindyktas Mts., Kurdai Pass $\}, 1200-1400$ м $\{\mathrm{m}\}, 14 . I V .1983$, собр. С.Л. Зонштейн, C.B. Овчинников \{S.L. Zonstein, S.V. Ovchinnikov\}.

Other types are kept in SMF.

Current status. Bolyphantes severtzovi Tanasevitch, 1989 (Linyphiidae).

\section{shumskyi Kovblyuk, 2003, Berlandina}

Kovblyuk, 2003: 880-882, fig. 1 (1-7, 10, 11)

Та-7268. Holotype $\sigma^{7}$, Украина, Крым, Симферопольский p-н, с. Лозовое, очень сухая степь на выходах порфирит-диабазов \{Ukraine, the Crimea, Simferopol Distr., Lozovoe, very dry steppe on porphyrite-diabase ourcrops $\}$, 4-18.IV.2000, Н.M. Ковблюк \{N.M. Kovblyuk .

Та-7269. Paratypes $12 \sigma^{7}$, Украина, Крым, Симферопольский р-н, с. Лозовое, очень сухая степь на выходах порфирит-диабазов \{Ukraine, the Crimea, Simferopol Distr., Lozovoe, very dry steppe on porphyrite-diabase ourcrops \}, 4-18.IV.2000, Н.M. Ковблюк \{N.M. Kovblyuk\}.

Та-7270. Paratype + , Украина, Крым, Симферопольский рн, с. Лозовое, очень сухая степь на выходах порфирит-диабазов \{Ukraine, the Crimea, Simferopol Distr., Lozovoe, very dry steppe on porphyrite-diabase ourcrops $\}, 23$.VI-16.VII.2000, H.M. Ковблюк \{N.M. Kovblyuk .

Ta-7271. Paratype + , Украина, Крым, Симферопольский рн, с. Лозовое, очень сухая степь на выходах порфирит-диабазов \{Ukraine, the Crimea, Simferopol Distr., Lozovoe, very dry steppe on porphyrite-diabase ourcrops $\}$, 26.VII-8.VIII.2000, Н.M. Ковблюк \{N.M. Kovblyuk\}.

Other types are kept in TNU.

Current status. Berlandina shumskyi Kovblyuk, 2003 (Gnaphosidae).

\section{sibirica Tanasevitch, 2007, Carorita}

Tanasevitch, 2007: 147-150, figs 26-32, 41-43.

Ta-7185. Holotype $\sigma^{7}$, Russia, Tyumen Area, Khanty-Mansi Autonomous Region, Surgutskiy District, Yuganskiy Nature Reserve, $59^{\circ} 45^{\prime} \mathrm{N}, 74^{\circ} 39^{\prime} \mathrm{E}$ (centre of the reserve), Nyogus'yakh River basin near Petchpan'yakh River mouth. Mosses and litter on large swamp. 13.IX.2000. A.<B.> Ryvkin.

Ta-7186. Paratypes $1 \Im^{\prime}, 10$ 우, Russia, Tyumen Area, Khanty-Mansi Autonomous Region, Surgutskiy District, Yuganskiy Nature Reserve, $59^{\circ} 45^{\prime} \mathrm{N}, 74^{\circ} 39^{\prime} \mathrm{E}$ (centre of the reserve), Nyogus'yakh River basin near Petchpan'yakh River mouth. Mosses and litter on large swamp. 13.IX.2000. A. $<$ B. $>$ Ryvkin.

Ta-7187. Paratype $\sigma^{7}$, Amurskaya Area, Selemdzhinskiy District, Norskiy N.R., $52^{\circ} 20^{\prime} \mathrm{N}, 1^{\circ} 9^{\circ} 51^{\prime} \mathrm{E}$, Nora River basin, near southern side of flood-plain lake, 30.VIII.2004, A.<B.> Ryvkin.

Ta-7188. Paratype + , Amurskaya Area, Selemdzhinskiy District, Norskiy N.R., Maltsevskoye Lake, mosses and leaf litter on swampy lakeside with tussocks of Poaceae, Carex, Spiraea, 11.VI. 2005, <A.B. $>$ Ryvkin and <E.M. $>$ Veselova.

Ta-7189. Paratype $\sigma^{7}$, Amurskaya Area, Selemdzhinskiy District, Norskiy N.R., Burunda River basin, $0.5 \mathrm{~km} \mathrm{NW}$ of Burunda 
Cordon, sedge-gramineous mesotrophic swamp with Sphagnum girgensohnii and true mosses around lake, 10.IX.2004, A.<B.> Ryvkin.

Ta-7190. Paratype + , Amurskaya Area, Selemdzhinskiy District, Norskiy N.R., Burunda River basin, $1.5 \mathrm{~km} \mathrm{NW}$ of Burunda Cordon, plant debris among tussocks of Carex, under sparse Alnus with young growth of Larix gmelinii along river bank near road, 17.IX.2004, A.<B.> Ryvkin.

Ta-7191. Paratype 9 , Khabarovsk Province, Bolshekhekhtsyrskiy N.R., near Chirki Cordon $\left(48^{\circ} 11^{\prime} \mathrm{N}, 134^{\circ} 41^{\prime} \mathrm{E}\right)$, bank of Ussuri River, hummocky herb-Calamagrostis swamp, 4.VI.2004, A. $<$ V. $>$ Tanasevitch.

Other types are kept in AT.

Current status. Carorita sibirica Tanasevitch, 2007 (Linyphiidae).

\section{sibiricus Eskov, 1987, Ceraticelus}

Eskov, 1987: 1750-1751, fig. 2(1-3)

Тa-5154. Holotype $\sigma^{7},<$ Красноярский край,> Енисей, $62^{\circ} 20^{\prime} \mathrm{N}$, окр. Мирного, р. Варламовка, безлесное сфагновогипновое болото с карликовой берёзкой \{Krasnoyarsk Prov. Yenisei, $62^{\circ} 20^{\prime} \mathrm{N}$, env. of Mirnoe, Varlamovka River, forestless Sphagnum-Hypnum bog with small dwarf birch\}, 3.IX.1979, собр К.Ю. Еськов $\{\mathrm{K} . \mathrm{Yu}$. Eskov\}.

Ta-5155. Paratype + , $<$ Красноярский край, $>$ Енисей, 62²0’ $\mathrm{N}$, окр. Мирного, р. Варламовка, безлесное сфагново-гипновое болото с карликовой берёзкой \{Krasnoyarsk Prov., Yenisei, $62^{\circ} 20^{\prime} \mathrm{N}$, env. of Mirnoe, Varlamovka River, forestless SphagnumHypnum bog with small dwarf birch\}, 3.IX.1979, собр. К.Ю Еськов $\{$ K.Yu. Eskov .

Та-5156. Paratype $q,<$ Красноярский край, $>$ Енисей, $62^{\circ} 20^{\prime}$ $\mathrm{N}$, окр. Мирного, p. Варламовка, заболоченное еловое редколесье, в долине ручейка \{Krasnoyarsk Prov., Yenisei, $62^{\circ} 20^{\prime} \mathrm{N}$ env. of Mirnoe, Varlamovka River, swampy spruce sparse forest in stream valley\}, 10-16.VIII.1979, К.Ю. Еськов \{K.Yu. Eskov\}.

Ta-5157. Paratype + , <Красноярский край, $>$ Енисей, $62^{\circ} \mathrm{N}$ p. Малая Лебедянка, берег озера, заросший ерником \{Krasnoyarsk Prov., Yenisei, $62^{\circ} \mathrm{N}$, Malaya Lebedyanka River, lake shore with ernik [= dwarf birch - willow thicket] $\}, 19$.VII.1986, Б.И. Шефтель \{B.I. Sheftel\}.

The types are kept in ZMMU only.

Current status. Synonymized with Ceraticelus bulbosus (Emerton, 1882) (Linyphiidae) [Helsdingen, 1995].

\section{spasskyi Ponomarev, 1979, Berlandina}

Ponomarev, 1979: 922-923, fig. 7 .

Ta-7313. Paratype + , 18.11.4/1. Калмыкия, Черноземельский p-н, пос. Рыбачий, ровный полупустынный участок с полыннозлаковой растительностью \{Kalmykia, Chernozemelskiy Distr. Rybachiy, plain semidesert with wormwood-gramineous vegetation\}, 20.VI.1974, собр. <A.B.> Пономарев \{A.V. Ponomarev\}.

Other types (holotype, paratypes) are kept in ZIN.

Current status. Berlandina spasskyi Ponomarev, 1979 (Gnaphosidae).

\section{stepposus Logunov, 1991, Bianor}

Logunov, 1991: 51-54, fig. 2 (1-7)

Ta-4600. Holotype $\sigma^{7}$, Тува, Эрзинский район, пески ЭдерЭлезин, оз. Тере-Холь, 1150-1200 м, куртины ковыля \{Tuva, Erzin Distr., Eder-Elezin Sands, Tere-Khol Lake, 1150-1250 m a.s.1., feathergrass clumps\}, 8-9.VIII.1989, собр. Д.В. Логунов $\{$ D.V. Logunov\}

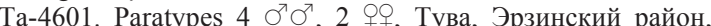
пески Эдер-Элезин, оз. Тере-Холь, 1150-1200 м, куртинь ковыля \{Tuva, Erzin Distr., Eder-Elezin Sands, Tere-Khol Lake, 1150-1250 m a.s.1., feathergrass clumps\}, 8-9.VIII.1989, собр. Д.В. Логунов $\{$ D.V. Logunov $\}$.

Ta-4602. Paratype + , Монголия, Селенгинский аймак, Шамор \{Mongolia, Selenga Aimak, Shamaar\}, 29.VII.1982, укосы \{sweeping\}, собр. К.Г. Михайлов \{K.G. Mikhailov\}.
Ta-4603. Paratype $\sigma^{7}$, Тува, окрестности (5-7 км к 3) Кызыла, агробиостанция, 700 м, куртины чия \{Tuva, env. (5-7 km W) of Kyzyl, pedagogical institute's agrobiostation, ca. $700 \mathrm{~m}$ a.s.l., Achnatherum clumps $\}, 25 . V .1989$, собр. Д.В. Логунов \{D.V. Logunov\}.

Other types are kept in ISEA.

Current status. Pellenes stepposus (Logunov, 1991) (Salticidae).

suhartoi Prószyński et Deeleman-Reinhold, 2013,

\section{Bavia}

Prószyński, Deeleman-Reinhold, 2013: 117, figs 10-20.

Ta-7776. Paratype + , Borneo, C. Kalimantan, "Kaharian", $2^{\circ} 02^{\prime} \mathrm{S}, 115^{\circ} 40^{\prime} \mathrm{E}$, peat bog forest, 2.IX.[19]85, leg. Suh. Djodjosudharmo.

Other types (holotype, paratypes) are kept in CD.

Current status. Bavia suhartoi Prószyński et DeelemanReinhold, 2013 (Salticidae).

tanasevitchi Marusik, Omelko et Koponen, 2016,

\section{Bifurcia}

Marusik et al., 2016: 81-83, figs 4-5, 15-21, 26-29.

Ta-7811. Holotype + , [English label:] Russia, Maritime Prov., Lazovskii Dist., Lazo Reserve, Sukhoi Klyuch gorge, closed scree in oak forest, south slope, 21.06.1981, T.I. Oliger [identical Russian label with differing date:] Приморье, Лазовский зап-к, уроч. Сухой ключ, закр. осыпь в дубраве, ю. склон, 22.VI.81, <Т.И.> Олигер \{T.I. Oliger\}.

Ta-7812. Paratype 9 , Russia, Maritime Prov., Lazovskii Dist., Lazo Reserve, Syao-Changou gorge, mountain slope, debris under stones, 13.08.1981, T.I. Oliger.

Ta-7813. Paratypes $4 \sigma^{\top} \sigma^{7}, 19$ of, Russia, Maritime Prov., Lazovskii Dist., Lazo Reserve, Sukhoi Klyuch gorge, scree in oak forest, under stones, 21.06.1981, T.I. Oliger.

Althouth in the original description [Marusik et al., 2016] other studied types were mentioned as being deposited in MMUE, actually they have never been placed there and their whereabouts is unknown (D.V. Logunov, pers. comm.).

Current status. Bifurcia tanasevitchi Marusik, Omelko et Koponen, 2016 (Linyphiidae).

ussuricus Eskov et Marusik, 1992, Centromerus

Eskov, Marusik, 1992: 40-41, fig. 3a-c.

Та-5265. Holotype $\sigma^{7}$, Приморье, Уссурийский запов., долинный кедровник \{Primorie [= Maritime Prov.], Ussuri Reserve, valley Pinus sibirica forest\}, 30.IX.1977, собр. Г.Ф. Курчева, Е.В. Михалёва \{G.F. Kurcheva, E.V. Mikhaljova\}.

Ta-5266. Paratypes 2 ㅇ, <Приморье,> Уссурийский заповедник \{Primorie [= Maritime Prov.], Ussuri Reserve\}, 3.VII. 1980, В.В. Белов \{V.V. Belov\}.

The types are kept in ZMMU only.

Current status. Centromerus ussuricus Eskov et Marusik, 1992 (Linyphiidae).

yakovlevi Marusik, Fomichev et Omelko, 2014,

\section{Berlandina}

Marusik et al., 2014: 204-208, figs 83-93.

Ta-7724. Paratype $\sigma^{7}$, Mongolia, Khovd Aimag, $33 \mathrm{~km} \mathrm{SW}$ from Altai Village, Bodonchiyn-Gol River Valley $\left(45^{\circ} 46^{\prime} 17^{\prime \prime} \mathrm{N}, 92^{\circ} 12^{\prime} 52^{\prime \prime} \mathrm{E}\right)$, stony desert, $1300 \mathrm{~m}, 6-7.05 .2012$, leg. Fomichev A.A.

Other types (holotype, paratypes) are kept in ISEA.

Current status. Berlandina yakovlevi Marusik, Fomichev et Omelko, 2014 (Gnaphosidae).

Acknowledgements. I am cordially obliged to my colleague Dmitry V. Logunov (Manchester, UK) for reviewing the manuscript and linguistic help. This paper is supported by the Moscow State University Project No. AAAA-A16116021660077-3. 


\section{References}

Eskov K.Yu. 1979. [Three new spider species of the family Linyphiidae (Aranei) from Siberia] // Balashov Yu.S. (ed.). Fauna i ekologiya paukoobraznykh. Trudy Zoologicheskogo Instituta AN SSSR. Vol.85. P.65-72 [in Russian].

Eskov K.Yu. 1987. [Spiders of Neartic genera Ceraticellus and Islandiana (Aranei, Linyphiidae) in the fauna of Siberia and Far East] // Zool. zhurn. Vol.66. No.11. P.1748-1752 [in Russian, with English summary].

Eskov K.Yu. 1988. [Seven new monotypic genera of spiders of the family Linyphiidae (Aranei) from Siberia] // Zool. zhurn. Vol.67. No.5. P.678-690 [in Russian, with English summary].

Eskov K.Yu. 1992. A restudy of the generic composition of the linyphiid spider fauna of the Far East (Araneida: Linyphiidae) // Ent. scand. Vol.23. P.153-168.

Eskov K.Yu., Marusik Yu.M. 1992. The spider genus Centromerus (Aranei Linyphiidae) in the fauna of Siberia and the Russian Far East, with an analysis of its distribution // Arthropoda Selecta. Vol.1. No.2. P.33-46.

Esyunin S.L., Ponomarev A.V. 2018. Taxonomic remarks on the genus Bogdocosa Ponomarev et Belosludtsev, 2008 (Aranei Lycosidae) // Arthropoda Selecta. Vol.27. No.1. P.61-68.

Evtushenko K.V. 1993. A new species of the genus Carpathonesticus (Aranei Nesticidae) from the East Carpathians of Ukraine / Arthropoda Selecta. Vol.2. No.3. P.61-63.

Fet V. 1993. The spider genus Cedicus Simon 1875 (Arachnidae Aranei Agelenidae) from Middle Asia // Arthropoda Selecta. Vol.2. No.1. P.69-75.

Guseinov E.F., Marusik Yu.M., Koponen S. 2005. Spiders (Arachnida, Aranei) of Azerbaijan. 5. Faunistic review of the funnelweb spiders (Agelenidae) with description of new genus and species // Arthropoda Selecta. Vol.14. No.2. P.153-177.

Helsdingen P.J., van. 1995. Ceraticelus bulbosus (Emerton, 1882) (Araneae, Linyphiidae), een ouder synonien van Ceraticelus sibiricus Eskov, 1987, in Nederland gevonden // Nieuwsbrief Spined. No.9. P.1-4.

Jäger P. 2000. The huntsman spider genus Cebrennus: four new species and a preliminary key to known species (Araneae, Sparassidae, Sparassinae) // Rev. arachnol. T.13. Fasc.12. P.163-186

Kovblyuk N.M. 2003. [Two new spider species of the family Gnaphosidae (Aranei) from Crimea] // Zool. zhurn. Vol.82. No.7. P.880-883 [in Russian, with English summary].

Kroneberg A.I. 1875. [A.P. Fedchenko. Voyage in Turkestan. Spiders. Araneae] // Izvestiya Obshchestva lyubitelei estestvoznaniya, antropologii i etnografii. Vol.19. No.3. P.I-IV, 1-55, 5 tabs [in Russian].

Logunov D.V. 1991. [Spiders of the family Salticidae (Aranei) from Tuva. 1. Six new species from the genera Sitticus, Biano and Dendryphantes] // Zool. zhurn. Vol.70. No.6. P.50-60 [in Russian, with English summary].

Logunov D.V. 2001. A redefinition of the genera Bianor Peckham \& Peckham, 1885 and Harmochirus Simon, 1885, with the establishment of a new genus Sibianor gen.n (Aranei: Salticidae) // Arthropoda Selecta. Vol.9 (for 2000). No.4. P.221-286.

Marusik Yu.M., Fomichev A.A., Omelko M.M. 2014. A survey of East Palaearctic Gnaphosidae (Araneae). 1. On the Berlandina Dalmas, 1922 (Gnaphosinae) from Mongolia and adjacent countries // Zootaxa. Vol.3827. No.2. P.187-213.

Marusik Yu.M., Gnelitsa V.A. 2009. A remarkable new species of Ceratinella Emerton, 1882 (Araneae, Linyphiidae, Erigoninae) from the Russian Far East // Acta zootaxon. sin. Vol.34. No.4. P.722-724.

Marusik Yu.M., Omelko M.M., Koponen S. 2016. Two new Bifurcia species (Aranei: Linyphiidae: Micronetinae) from Far East Russia // Arthropoda Selecta. Vol.25. No.1. P.77-83.

Mikhailov K.G. 2016a. Arachnid types in the Zoological Museum, Moscow State University. I. Opiliones (Arachnida) // Arthropoda Selecta. Vol.25. No.3. P.327-334.

Mikhailov K.G. 2016b. [Arachnology in Russia/USSR] // Pavlinov I.Ya., Kalyakin M.V., Sysoev A.V. (eds.). Aspects of biodiversity. Part 2. Archives of Zoological Museum of Moscow State University. Vol.54. No.2. P.655-691 [in Russian, with English summary].
Mikhailov K.G. 2018a. Arachnid types in the Zoological Museum of the Moscow State University. II. Aranei 1 (Arachnida) // Arthropoda Selecta. Vol.27. No.1. P.95-105.

Mikhailov K.G. 2018b. Arachnid types in the Zoological Museum of the Moscow State University. III. Aranei 2 (Arachnida) // Arthropoda Selecta. Vol.27. No.2. P.177-186.

Mikhailov K.G., Ivanov D.L. 2018. [Type collections of the invertebrates in the Zoological Museum of Moscow State University] // Biologicheskie kollektsii segodnya i zavtra. Zoologicheskie issledovaniya. No.20. Moscow: KMK Scientific Press. P.190191 [in Russian and English].

Oliger T.I. 1999. A new Atypus from the Russian Far East (Aranei: Atypidae) // Arthropoda Selecta. Vol.7 (for 1998). No.3. P.201204.

Ponomarev A.V. 1979. [New spider species of the family Gnaphosidae from Northern Ciscaspia] // Zool. zhurn. Vol.58. No.6. P.921-923 [in Russian, with English summary].

Ponomarev A.V. 2007. [New taxa of spiders (Aranei) from the south of Russia and West Kazakhstan] // Caucasian Entomol. Bull. Vol.3. No.2. P.87-95 [in Russian, with English summary]

Ponomarev A.V. 2008. [Addition to the spider (Aranei) fauna of the south of Russia and Western Kazakhstan: new taxa and records] // Caucasian Entomol. Bull. Vol.4. No.1. P.49-61 [in Russian, with English summary].

Ponomarev A.V., Belosludtsev E.A., Dvadnenko K.V. 2008. [Spiders (Aranei) of Lower Povolzhie (Astrakhan and Volgograd areas), with descriptions of new taxa] // Caucasian Entomol. Bull. Vol.4. No.2. P.163-183 [in Russian, with English summary].

Ponomarev A.V., Tsvetkov A.S. 2006. [New and rare spider species of the family Gnaphosidae (Aranei) from the South-East of Europe] // Caucasian Entomol. Bull. Vol.2. No.1. P.5-13 [in Russian, with English summary].

Prószyński J., Deeleman-Reinhold Ch.L. 2013. Description of some Salticidae (Aranei) from the Malay Archipelago. III. Salticidae of Borneo, with comments on adjacent territories // Arthropoda Selecta. Vol.22. No.2. P.113-144.

Tanasevitch A.V. 1987. The linyphiid spiders of the Caucasus, USSR (Arachnida: Araneae: Linyphiidae) // Senckenberg. biol. Bd.67. H.4-6. P.297-383.

Tanasevitch A.V. 1989. The linyphiid spiders of Middle Asia (Arachnida: Araneae: Linyphiidae) // Senckenberg. biol. Bd.69. H.1/3. P.83-176.

Tanasevitch A.V. 1990. [Spiders of the family Linyphiidae of the Caucasian fauna (Arachnida, Aranei)] // Striganova B.R. (ed.). Fauna nazemnykh bespozvonochnykh Kavkaza. Moscow: Nauka Publ. P.5-114 [in Russian], 235 [English summary].

Tanasevitch A.V. 2000. New species of the family Linyphiidae from South Siberia, Russia (Arachnida: Araneae) // Reichenbachia. Bd.33. Nr.31. P.243-253.

Tanasevitch A.V. 2007. New linyphiid taxa from Siberia and the Russian Far East, with notes on the genera Notioscopus Simon and Carorita Duffey et Merrett (Aranei: Linyphiidae) // Arthropoda Selecta. Vol.15 (for 2006). No.2. P.141-152.

Tanasevitch A.V. 2009. The linyphiid spiders of Iran (Arachnida, Araneae, Linyphiidae) // Rev. suisse Zool. T.116. Fasc.3-4. P. 379-420

Tanasevitch A.V. 2011. On synonymy of linyphiid spiders of the Russian fauna (Arachnida: Aranei: Linyphiidae). 2 // Arthropoda Selecta. Vol.20. No.2. P.129-143.

Tanasevitch A.V. 2014. On the linyphiid spiders from Thailand and West Malaysia (Arachnida: Aranei: Linyphiidae) // Arthropoda Selecta. Vol.23. No.4. P.393-414.

Tanasevitch A.V., Esyunin S.L. 2013. A new Centromerus Dahl, 1886 from the Kirov Area, Russia (Aranei: Linyphiidae) // Arthropoda Selecta. Vol.22. No.4. P.357-360.

Tanasevitch A.V., Ponomarev A.V., Chumachenko Yu.A. 2015. Notes on the spider genus Bisetifer Tanasevitch, 1987 (Aranei: Linyphiidae), with the description of a new species // Arthropoda Selecta. Vol.24. No.4. P.445-450.

WSC. 2019. World Spider Catalog. Natural History Museum Bern, online at: http://wsc.nmbe.ch, version 20.0 (accessed on March 2nd, 2019).

Responsible editor D.V. Logunov 